\title{
Numerical Study on Performance Characteristics of Draft Tube of Mixed Flow Hydraulic Turbine
}

Ruchi Khare and Vishnu Prasad

\begin{abstract}
Draft tube is an important component of the hydraulic reaction turbine and affects the overall performance of turbine to a large extent. The flow inside the draft tube is complex because of the whirling flow coming out of runner and its diffusion along the draft tube. The kinetic energy coming out of runner is recovered in draft tube and part of recovery meets the losses. In the present work, the computational fluid dynamics (CFD) has been used for flow simulation in complete mixed flow Francis turbine for performance analysis for energy recovery, losses and flow pattern in an elbow draft tube used in Francis turbine at different operating conditions. The overall performance of the turbine at some typical operating regimes is validated with the experimental results and found to be in close comparison.
\end{abstract}

Key words: Draft tube, computational fluid dynamics, whirl, efficiency, energy recovery

\section{Introduction}

$\mathbf{T}$ The hydro power plays an important role in energy sector to meet increasing demand of energy. The hydraulic turbines convert hydro energy into electric energy and therefore, the increase in efficiency of turbine is a challenging task. Each component of turbine has some specific function and hence the design of every component of the turbine is equally important (Raabe 1985). But out of all components, draft tube converts kinetic energy coming out of runner into useful pressure energy which has otherwise been wasted. Therefore, the design of draft tube is important as it contributes in improvement of efficiency and also to overall performance of turbine.

A number of researchers have worked on the design and performance analysis of draft tube in the 19th century. The influence of length of elbow on the power characteristics of the turbine was first investigated by V.A. Solnishkov (Gubin 1973). The use of commercial software for design and performance analysis of the components of hydraulic machines was started in early 1980's (Buntić , Dietze and Ruprecht 2005, Marjavaara 2006) used a surrogate-based optimization (SBO) framework to optimize the shape of hydraulic turbine draft tubes. The problem of rope formation in the draft tube was analyzed and explained by various researchers (Hellstorm, Marjavaara and Lundström 2007; Tridon, Barre et al 2010).

Most of the time turbines operate at off design conditions and the performance of the draft tube is affected by operating turbine. No study has been reported for performance of draft tube under varying turbine operating regimes. It is difficult to predict detailed flow behavior in the draft tube by an experimental approach due to flow complexity and instrument limitations. Thus, a numerical flow simulation has become a cost effective approach (Sick, Michler et al 2009; Lain, Garcia et al 2010). The study of draft tube performance is required not only to improve the turbine efficiency but also to predict behavior of the complete machine for pitting, vibrations and other operational difficulties arising due to pressure and velocity pulsation and consequent cavitation in the draft tube, which can be predicted from pressure distribution within the draft tube.

In this paper, numerical flow simulation has been carried out for steady viscous turbulent flow in experimentally tested Francis turbine assembly consisting of casing, stay ring, distributor, runner and draft tube using Ansys CFX commercial CFD code, where control volume based finite element method is used for discretisation of Reynolds Average Navier Stokes (RANS) equations. As the flow passage has high curvature, the SST k- $\omega$ turbulence model has been used for simulation. The loss, efficiency and head recovery characteristics of the draft tube have been predicted at off design, rated head and over load conditions from simulation results. In addition, streamlined patterns in draft tubes at selected points are obtained, which may be useful to optimize the design of the complete turbine. The overall efficiency of the turbine is validated with the experimental results for typical operating conditions.

\section{Numerical Scheme for Discretisation}

The Ansys CFX uses a control volume based finite element method which is the hybrid of finite volume and finite element methods (Ansys CFX Manual 2005; Ferziger and Peric 2002). It uses triangular elements and linear interpolation functions as used in the finite element method (FEM). The control volumes, similar to the finite volume method (FVM) are generated around each node by joining the centroids of elements and midpoint of sides of element. The computational nodes are element vertices and interpolation functions are used to show the variation of variables over the element similar to FEM. Conservation equations in integral form, similar to FV method are used in this approach also. The surface and volume integrals are calculated element wise. The algebraic equations so obtained involve the variables at node $\mathrm{P}$ around which control volume is created and its immediate neighboring nodes $\left(\mathrm{N}_{1}-\mathrm{N}_{5}\right)$ as shown in figure 1. 


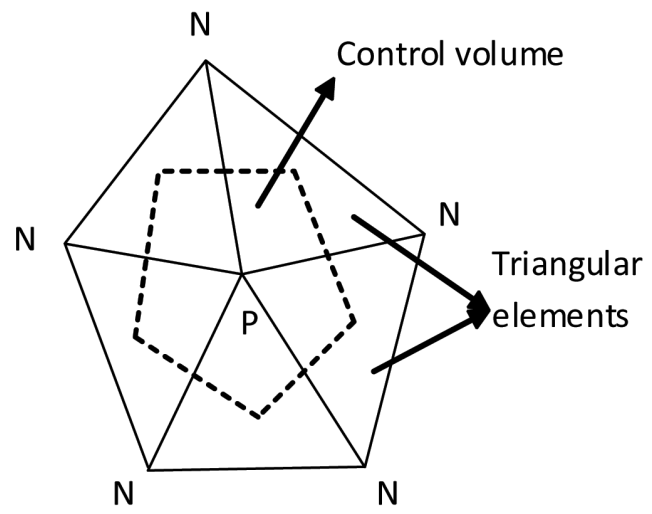

Figure 1. Control Volume on Triangular Elements.

\section{Geometry and Mesh Generation}

The CFD simulation for the draft tube can be done either for the draft tube alone or for the complete turbine assembly. As the flow from runner enters into the draft tube, hence, in the case of draft tube alone, it is difficult to specify the proper inlet boundary condition. Therefore, $3 \mathrm{D}$ geometry of complete turbine space is required for numerical simulation in Francis turbine. The geometry of each component of turbine - namely casing, stay ring, guide wheel, runner and draft tube - is created separately. These components are then assembled through proper interfaces for flow simulation in complete turbine space. The solid modeling of different components of turbine is done using Ansys Workbench. The elbow draft tube is composed of a cone frustum, an elbow and a diffuser with circular inlet and outlet. The geometric modeling of distributor is done for the three guide vane openings corresponding to off-load, rated load and overload operating conditions.

Unstructured tetrahedral mesh has been used in the complete turbine flow domain. It is generated using Ansys ICEM CFD. The quality of mesh is checked as it affects the accuracy of solution to a large extent. Quality checks are applied for duplicate elements, uncovered faces, missing internal faces, volume and surface orientations, single edges, overlapping elements and unconnected vertices. The size of mesh is taken such that the $\mathrm{y}+$ value is less than 200 which satisfies the requirement of turbulence model SST k- $\omega$ used in simulation (Ansy 2005). The summary of mesh elements for complete flow domain is given in Table 1 . The surface meshing of all components of turbine is shown in Figure 2.

\begin{tabular}{|c|c|c|c|}
\hline Part Name & No. of Nodes & No. of Elements & Element Type \\
\hline Casing & 58,753 & 284,057 & Tetrahedral \\
\hline Stay Ring & 103,695 & 503,894 & Tetrahedral \\
\hline Distributor & 140,466 & 679,734 & Tetrahedral \\
\hline Runner & 455,749 & $2,209,472$ & Tetrahedral \\
\hline Draft Tube & 273,923 & $1,425,659$ & Tetrahedral \\
\hline
\end{tabular}

Table 1. Mesh Data of All Domains of Francis Turbine.

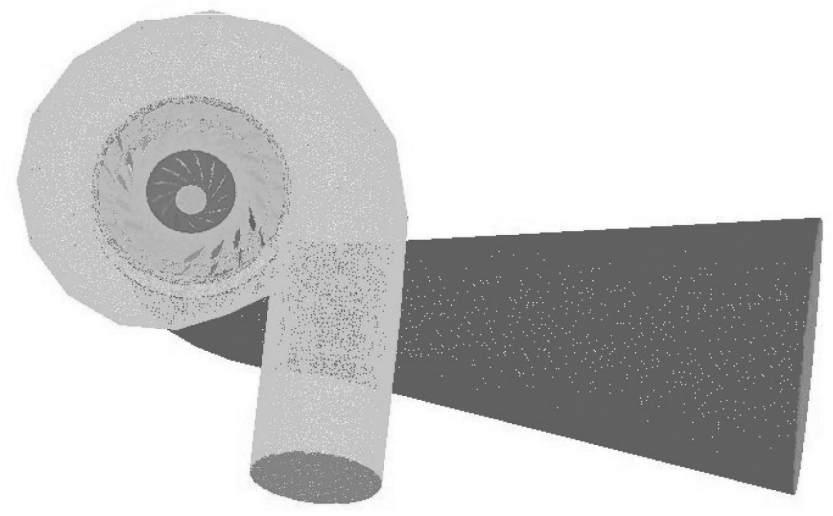

Figure 2. Meshing of Complete Assembly of Francis Turbine.

\section{Boundary Conditions}

As the geometry of all components has been considered for the flow simulation, hence the inlet boundary condition is specified at the casing inlet in terms of mass flow rate and the outlet boundary condition is specified at the draft tube outlet in terms of static pressure. The mass flow rates of $5,930 \mathrm{~kg} / \mathrm{s}, 7200 \mathrm{~kg} / \mathrm{s}$ and $8000 \mathrm{Kg} / \mathrm{s}$ at $66.73 \mathrm{~mm}, 80.93 \mathrm{~mm}$ and $91.57 \mathrm{~mm}$ Gate Valve (GV) opening respectively have been specified at inlet which are taken from experimental data. The best operating point lies at $7,200 \mathrm{~kg} / \mathrm{s}$ at $80.93 \mathrm{~mm} \mathrm{GV}$ opening. These mass flow rates are taken from model test data. The design speed of turbine is $600 \mathrm{rpm}$ and hence the rotational speed of runner is varied from $400 \mathrm{rpm}$ to $900 \mathrm{rpm}$ at an interval of $100 \mathrm{rpm}$ for each guide vane opening. The turbulence intensity of $5 \%$ is specified. The walls of all domains are taken as stationary with no slip condition. The frozen rotor interfacing is used between rotating and stationary domains.

\section{Formulae Used}

The following formulas are used for computation of non-dimensional hydrodynamic parameters:

Head loss

$$
\Delta \mathrm{h}_{\mathrm{D}}=\frac{\mathrm{TP}_{\mathrm{DI}}-\mathrm{TP}_{\mathrm{DE}}}{\gamma}
$$

Draft tube recovery (\%) $\quad v=\frac{1}{\mathrm{H}}\left(\frac{\mathrm{C}_{\mathrm{DI}}^{2}-\mathrm{C}_{\mathrm{DE}}^{2}}{2 \mathrm{~g}}-\Delta \mathrm{h}_{\mathrm{D}}\right) \times 100$

Draft tube efficiency (\%) $\eta_{\mathrm{d}}=\frac{\left(C_{\mathrm{DI}}^{2}-C_{\mathrm{DE}}^{2}-2 g \Delta h_{D}\right)}{\mathrm{C}_{\mathrm{DI}}^{2}} \times 100$

Relative loss coefficient

$$
\zeta=\frac{2 \mathrm{~g} \Delta \mathrm{h}_{\mathrm{D}}}{\mathrm{C}_{\mathrm{DI}}^{2}}
$$

Speed factor

$$
\mathrm{n}_{\mathrm{ED}}=\frac{\mathrm{nD}}{\sqrt{\mathrm{gH}}}
$$

\section{Results and Discussions}

The accuracy of numerical solution for entire turbine has been checked by varying the size of grid. I1 is seen in Figure 3 that as the grid size is reduced the efficiency of the turbine increases. Further reduction of the grid is not possible due to limitation for number of nodes in software.

The velocity coming out of runner has meridional 


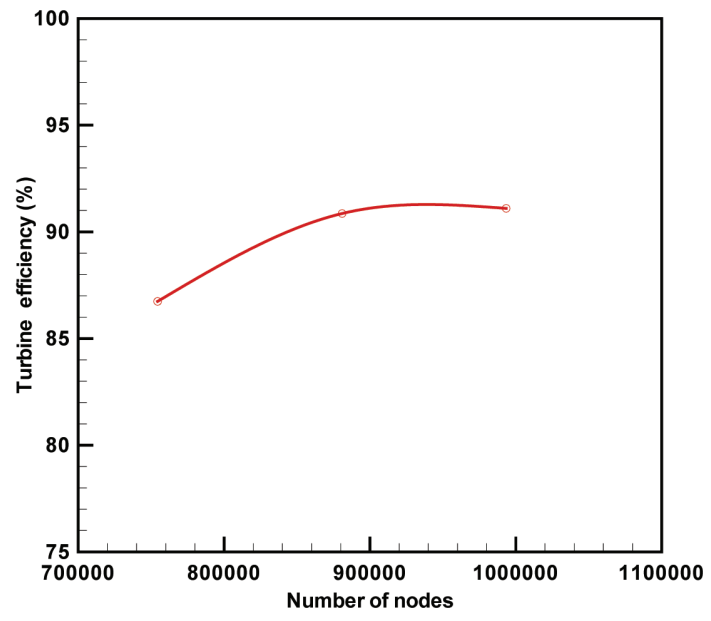

Figure 3. Grid Size Sensitivity Text.

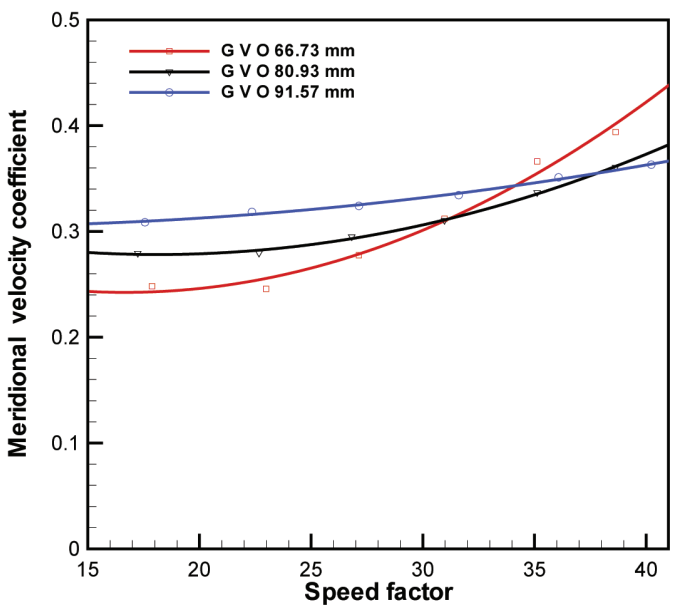

Figure 4. Variation of Meridional Velocity.

and whirl components and their variations are shown in Figures 4 and 5. It is observed in Figure 4 that the meridional velocity has gradual increase with speed factor and rate of increase is more at less Gate Valve Opening (GVO). The whirl velocity in Figure 5 increases linearly with speed at same rate for all GV opening, but at any speed factor there is decrease in whirl velocity with increase in GV opening.

It is seen in Figure 6 that draft tube efficiency has

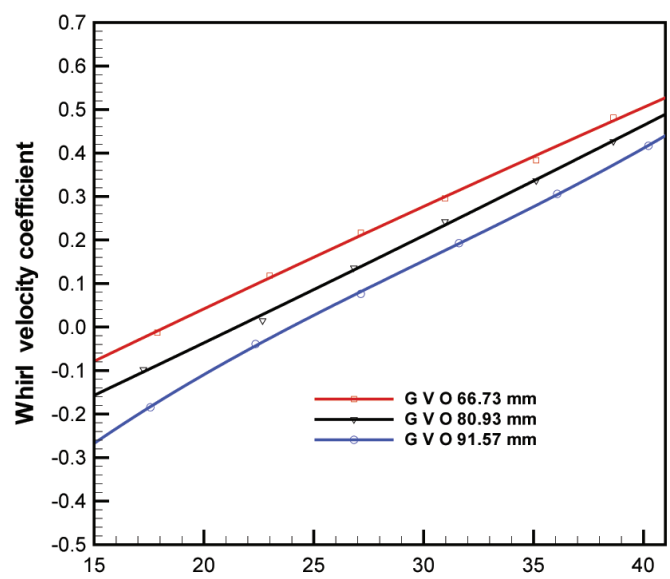

Figure 5. Variation of Whirl Velocity.

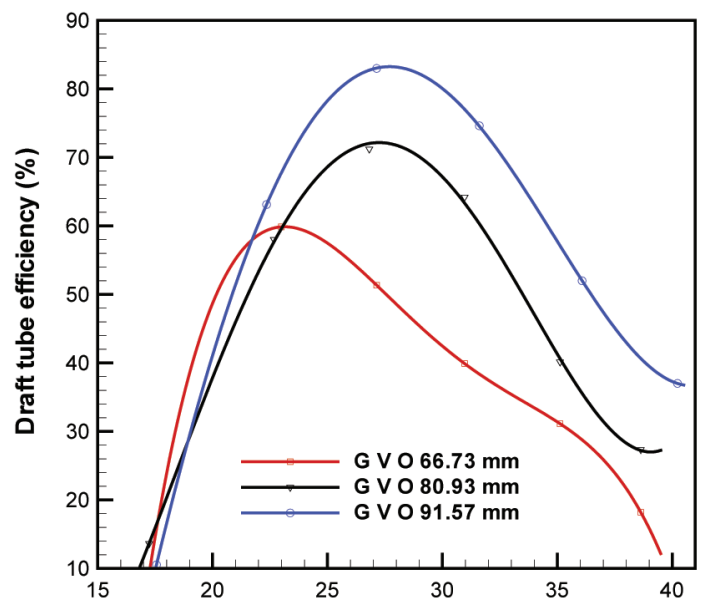

Figure 6. Variation of Draft Tube Efficiency.

parabolic variation with speed factor for all three GV opening. The point of maximum efficiency shifts towards higher speed factor and also its value increases as the guide vane opening is increased. The best efficiency is found at maximum GV opening as losses are the minimum at this opening.

The energy recovery in the draft tube increases with speed at all guide vane opening up to speed factor value 35 and then starts decreasing with further increase in speed as seen from Figure 7. The major part of head recovery in draft tube occurs from meridional velocity and hence head recovery increases with guide vane opening due to increased meridional velocity. The decrease of head recovery at higher speed factor may be due to much increased whirl velocity and its change of direction at outlet of runner as compared to meridional velocity. The plots of relative loss in draft tube, expressed as ratio head loss to inlet velocity head in Figure 8 have parabolic variation at all guide vane openings. The speed factor for minimum loss increases as the GV opening increases. The parabolic loss variation in draft tube is attributed to the variation of whirl and meridional velocities coming out of the runner.

The streamline patterns in draft tube at constant speed for three GV openings in Figure 9 show that the amount

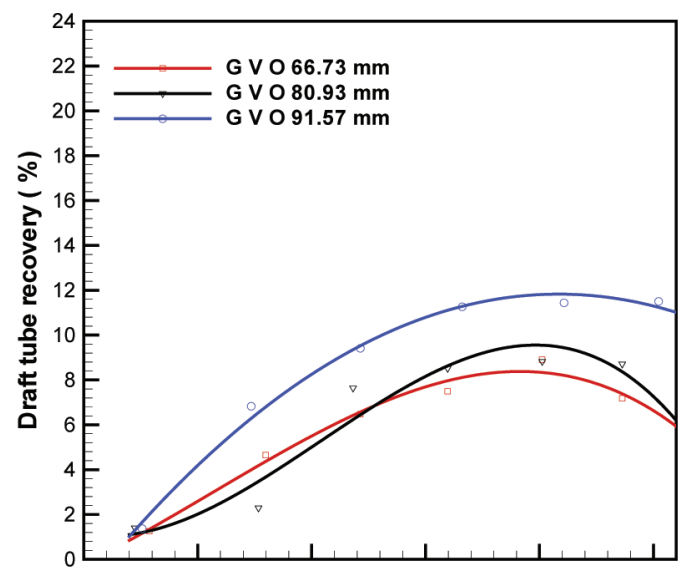

Figure 7. Draft Tube Recovery. 


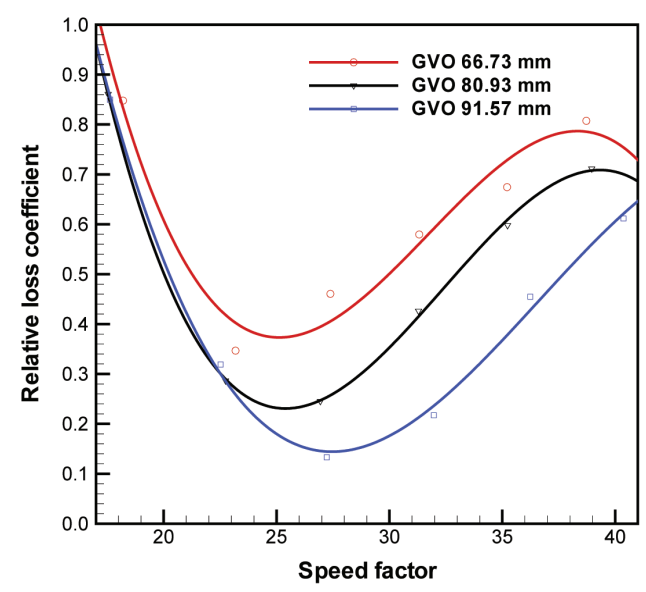

Figure 8. Relative Loss in Draft Tube

of whirl coming out of runner decreases with increase in GV opening. The maximum velocity zone is observed at the inner side of elbow in all three configuration of guide vane. The velocity reduces as flow moves from inlet to outlet of draft tube leading to conversion of kinetic energy into pressure energy. As the guide vane increases, flow at outlet becomes more eccentric and concentrated to smaller area. The flow line become almost parallel near the outlet at GV opening $=91.57 \mathrm{~mm}$.

Similarly, the stream line plots within the draft tube shown in Figure 10 for three rotational speeds; i.e., 400, 600 and $900 \mathrm{rpm}$ at constant GV opening of $80.93 \mathrm{~mm}$ indicate that amount of swirl coming out of runner is more for under and over speed. As seen from Figure 4 , the whirl velocity changes its direction of rotations near design speed and hence minimum swirl is seen at designed speed. Again, with the increase in speed at constant guide vane opening, flow at outlet becomes eccentric and concentrated to small area and also the flow lines near outlet become almost parallel at higher speed.

\section{Conclusions}

It is found that both meridional and whirl components of velocity coming out of runner are dependent on the operating regime of turbine and it is seen that these velocities in turn affect the losses and energy recovery in draft tube. The energy recovery increases up to certain speed factor and after that it starts decreasing but
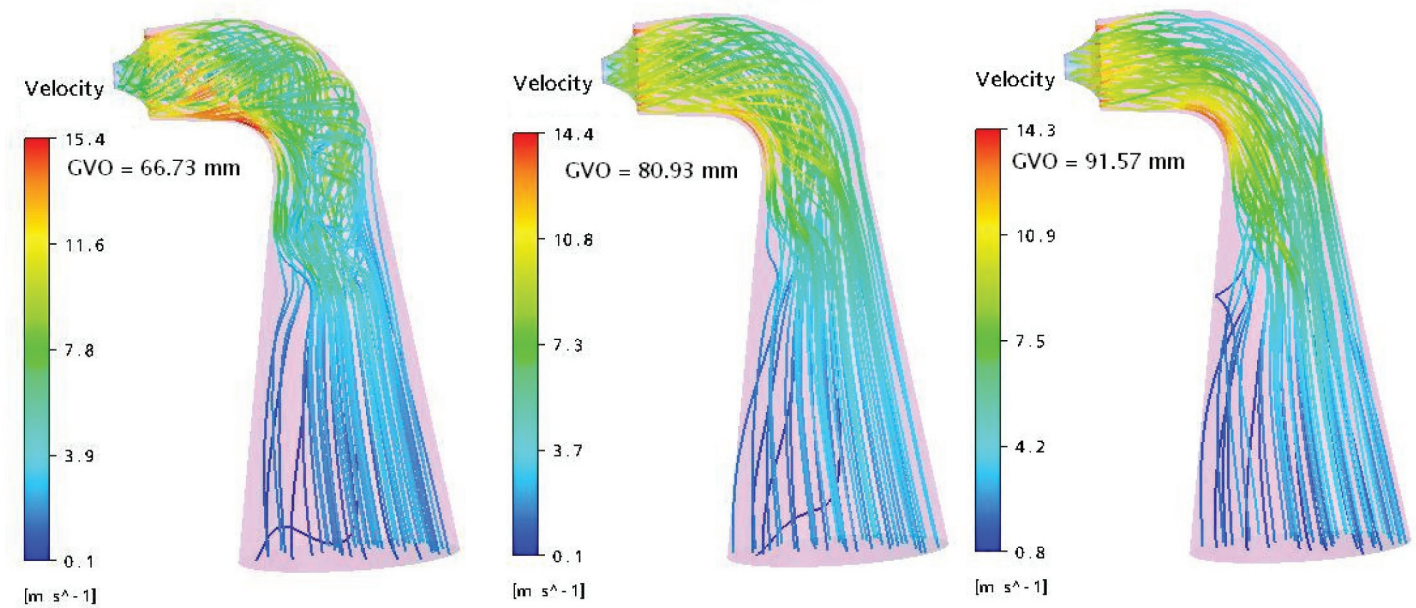

Figure 9. Stream Lines within Draft Tube at Three Guide Vane Openings at Speed of $600 \mathrm{rpm}$.
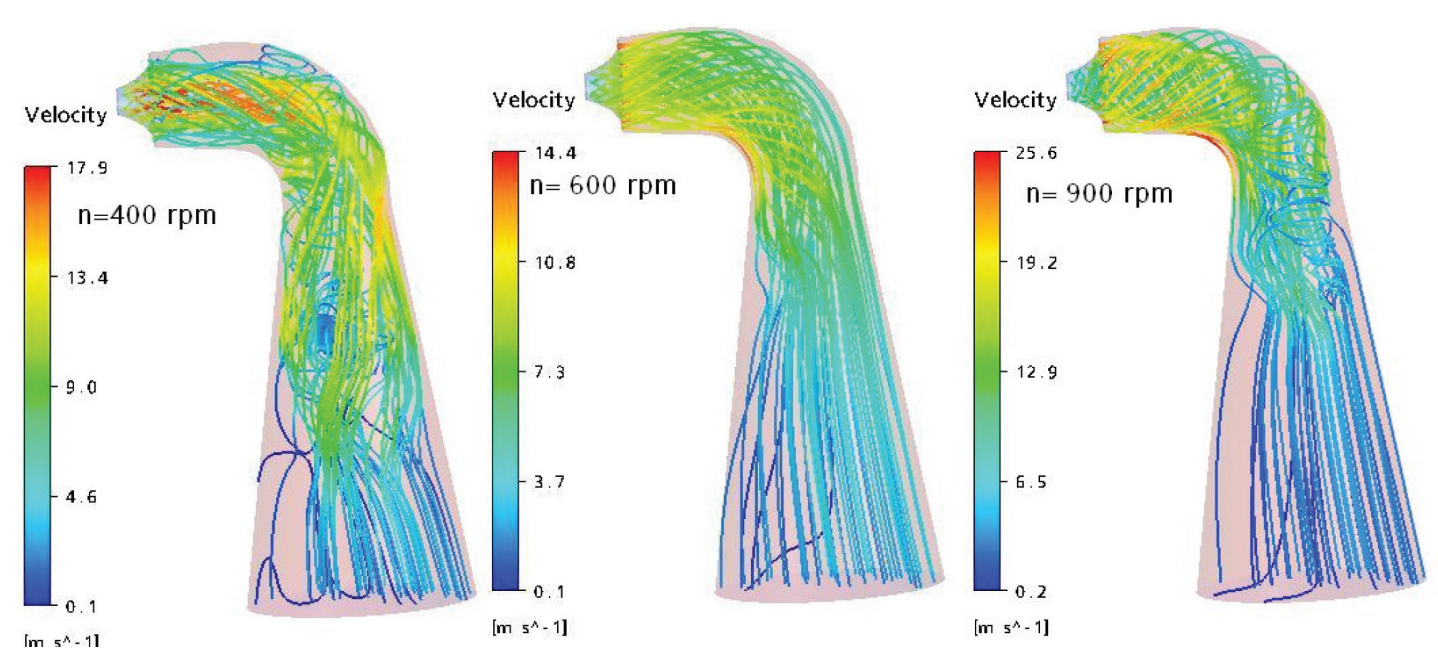

Figure 10. Stream Lines Within Draft Tube at Three Speeds for Constant GV Opening. 
increases continuously with GV opening. It is found that the draft tube loss and efficiency have parabolic variation with speed factor and the point of maximum efficiency or minimum loss shifts towards higher speed factor with increase in guide vane opening. The performance characteristics of draft tube and flow pattern within it will be useful for the design optimization of draft tube geometry to improve the performance of draft tube as well as turbine.

\section{Nomenclature}

$\begin{array}{ccl}\mathrm{C}_{\mathrm{DI}} & - & \text { Velocities }(\mathrm{m} / \mathrm{s}) \text { at draft tube inlet } \\ \mathrm{C}_{\mathrm{DE}} & - & \text { Velocities }(\mathrm{m} / \mathrm{s}) \text { at draft tube outlet } \\ \mathrm{D} & - & \text { Diameter of runner } \\ \mathrm{H} & - & \text { Net head }(\mathrm{m}) \\ \mathrm{TP}_{\mathrm{DI}} & - & \text { Total pressure at draft tube inlet }(\mathrm{Pa}) \\ \mathrm{TP}_{\mathrm{DE}} & - & \text { Total Pressure at draft tube outlet }(\mathrm{Pa}) \\ \mathrm{G} & - & \text { Acceleration due to gravity }\left(\mathrm{m} / \mathrm{s}^{2}\right) \\ \Delta \mathrm{h}_{\mathrm{D}} & - & \text { Head loss }(\mathrm{m}) \text { in draft tube } \\ \mathrm{N} & - & \text { Speed of runner (rpm) }\end{array}$

Prof. Ruchi Khare, M. Tech (Hydro), 1992 from Maulana Azad National Institute Of Technology (MANIT), Bhopal, India, PhD submitted. She is presently pursuing research and consultancy in hydraulic turbines. She has published more than 29 papers in various national and international journals and conferences. She is a life member of Indian Society of Technical Education (ISTE) and National Society of Fluid Mechanics and Fluid Power.

Corresponding address: ruchif4@rediffmail.com

Prof. Dr. Vishnu Prasad, M. Tech (Water Resources Engineering), 1988, from the Indian Institute of Technology (IIT), Bombay, PhD in Hydro Turbines from the Rajiv Gandhi Proudyogiki Vishwavidyalaya (State Technological University of Madhya Pradesh, India) (RGPV) in Bhopal in 2009. He is presently providing consultancy services and conducting research in hydraulic turbines and water resources. He has been trained in the UK on model testing and computational fluid dynamics for six months. He has published over 50 papers in national and international journals and conferences. He is member of Institution of Engineers (India) and life member of Indian Society of Water Resources and National Society of Fluid Mechanics and Fluid Power.

Corresponding address: vpp7@yahoo.com

\section{References}

Ansys, 2005, Ansys CFX 10.o User Manual, Canonsburg, Pennsylvania: Ansys Inc.

Buntić, O.I., S. Dietze and A. Ruprecht, 2005, 'Numerical simulation of the flow in elbow draft tube of Turbine99', pp.1-8 in Proceeding of the Third IAHR/ ERCOFTAC Workshop on Draft Tube Flow, Porjus, Sweden.

Ferziger J.H. and M. Peric, 2002, Computational Methods for Fluid Dynamics, Berlin, Heidelberg and New York: Springer Verlag.

Gubin M.F., 1973, Draft Tubes of Hydro-Electric Stations, New Delhi: Amarind.

Hellstorm J.G.I., B.D. Marjavaara and T.S. Lundström, 2007, 'Parallel CFD simulations of an original and redesigned hydraulic turbine draft tube', Journal of Advances in Engineering Software 38:338-344.

Lain, S., M. Garcia, B. Quintero and S. Orrego, 2010, 'CFD Numerical Simulations of Francis Turbine', Rev. Fac. Ing. Univ. Antioquia 51:24-33.

Marjavaara, D.B., 2006, CFD Driven Optimization on Hydraulic Turbine Draft Tubes Using Surrogate Models, PhD dissertation, Lulea University of Technology, Department of Applied Physics and Mechanical Engineering, Lulea, Sweden.

Raabe, J., 1985, Hydro Power: The Design, Use and Function of Hydro Mechanical Hydraulic and Electrical Equipment, Dusseldorf: VDI-Verlag $\mathrm{GmbH}$.

Sick M., W. Michler, T. Weiss and H. Keck, 2009, 'Recent developments in dynamic analysis of water turbines', Journal of Power and Energy 223(A):415-427.

Tridon, S., S. Barre, G.D. Ciocan and T. Laurent, 2010, 'Experimental analysis of the swirling flow in a Francis Turbine draft tube: Focus on radial velocity component determination', European Journal of Mechanics B/Fluids 29:321-325.

\section{CALENDAR OF EVENTS - IRRIGATION}

11-13 April, 2012: Asian Irrigation Forum. Location: Manila , Philippines. Organized by Asian Development Bank. More Info: www.beta.adb.org/ news/events/asian-irrigation-forum-2012.

4-30 June, 2012: ICID and Irrigation Australia Conference. Location:Adelaide, Australia. More Info: online.saneevent.com.au/ial2012/.

16-20 July, 2012: International Symposium on Irrigation of Horticulture Crops. Location: Weinstadt-Beautelsbach, Germany. More Info: www.biztradeshows.com/conferences/irrigation-horticultural-crops/.

11-13 December, 2012: 4th International Conference on Sustainable Irrigation and Drainage: Management, Technologies, and Policies. Location: Adelaide, Australia. More info: www.wessex.ac.uk/12conferences/sustainable-irrigation-2012.html.

12 March, 2012: National seminar on irrigation for food security. Location: Kathmandu, Nepal, contact: smtp.doi@yahoo.com. 